\title{
Designing a Mobile Application for Structured and Flexible Interview Data Collection in the Health Domain
}

\author{
https://doi.org/10.3991/ijim.v12i3.8232 \\ Tanja Svarre ${ }^{(\varpi)}$ \\ Aalborg University, Aalborg, Denmark \\ tanjasj@hum.aau.dk \\ Tine Bieber Kirkegaard Lunn \\ University College of Northern Denmark, Aalborg, Denmark
}

\begin{abstract}
The purpose of this paper is to report on the design of an Android tablet application for data collection by occupational therapists. The design emerged from two design workshops held with users experienced in collecting data on the challenges clients face in using technologies in their daily lives. On the basis of information gathered in the workshops, an Android application was developed for use in clinical and research settings. The aim was to ease the data-collection process and improve data quality by digitizing an existing analogue tool.
\end{abstract}

Keywords-user involvement, occupational therapy, health information technology, mobile healthcare application

\section{Introduction}

Mobile health care enables healthcare provision without geographical, temporal, or organizational constraints, which allows higher-quality services to be provided to citizens and widens the coverage area [1], [2]. In other words, health care can be carried out and documented on site using mobile technologies. As such, mobile health care is part of the general digitization of the health domain that has been underway for some time. It relies on communication and the use of various software applications for diagnosing and medical calculation purposes, and provides access to information resources and information systems [3]. The expected and documented benefits of digital health care include improved safety, reduced costs, higher quality, and fewer errors [4]-[6]. However, the field has also experienced challenges, especially in relation to design and implementation. These challenges include questions about reliability, a lack of usability, adoption issues, and a lack of user involvement in design and development [3], [4], [7]. Although the digitization of health care holds great potential, it should be carefully developed and implemented.

Mobile health care has a variety of goals, such as disease prevention, monitoring, remote care, decision-making support, and emergency intervention [8]. Varshney [8] classifies mobile-health applications in terms of whether they are user or provider 
centric, and whether they are automated or human assisted. In recent years, the range of self-reporting health-related mobile applications has increased. Individuals can monitor and track their own health using mobile applications (e.g., pulse, movement, exercise), and applications can guide individuals' health-related decisions (e.g., walk more, eat less).

The mobile health application addressed in this paper originated from an established, paper-based tool used in occupational practice and research to collect data on clients' use of technologies in their daily lives. The tool is used to identify a client's perceived difficulties with those technologies and whether those technologies are relevant to the focal client [9], [10]. The data collected using the tool are important for determining a client's ability to independently carry out a range of activities in everyday life. As the tool is commonly used with clients suffering from cognitive impairment, such as dementia, self-reporting is not an option. Furthermore, the tool requires a semi-structured conversation between the occupationat therapist and the client and contains questions grouped into seven topics. It covers a total of 90 technologies. Due to the focal client group and the tool's complexity, the tool was developed to be handled by professional data collectors.

In its original form, the tool consisted of 13 pages that were printed and filled out by the data collector during a conversation with the client. The intentions of transforming the tool to a digital form were to increase flexibility in the tool's use and to improve the data quality by, for example, eliminating the risk of errors when transferring data from paper to clients' journals or when using the data in situations requiring team collaboration.

\section{$2 \quad$ Related work}

Mobile technologies have gained some attention in occupational therapy. Most applications have been developed to enable clients to report observations and information for future interventions with therapists. Recent examples include Almeida et al.'s [11] application for the self-management of psychotic disorders and Svarre et al.'s [12] application for identifying barriers in clients' homes.

The use of standardized instruments for collecting client data is common in occupational therapy [12]. However, the tools are rarely available in digital form. Thus, little research to date has focused on mobile health solutions targeting occupational therapists and their collection of data for documentation purposes. In general, mobile health care has gained a lot of attention in a variety of medical fields [13], also in terms of professionals' usage [14]. In this regard, solutions range from mobile applications focused on a specific aspect of health to applications providing access to health-record systems from a distance. The aims of such applications are to provide clinical support, health-worker support, and helpline functions, and enable remote data collection [15]. The expectation is that occupational therapy, which generally involves numerous home visits, would benefit from a move toward mobile health care, as has been the case in many other areas in the health domain. 


\section{$3 \quad$ Methodology}

Design workshops were used to gain an understanding of users' requirements for the future mobile application. Two design workshops were held in the early stages of the development process (December 2015). As the workshops were to take place in Stockholm, we invited participants who lived within a reasonable distance of the city. Two types of participants took part in the workshops. One group had experience in using the original tool for data collection for research purposes (six participants), while the second group was experienced in using it in clinical practice (three participants). As the tool was most commonly used in Sweden at the time of the workshops, all participants were Swedish.

At the beginning of the workshops, all participants completed informed consent forms. The workshops were based on fictional narratives [16] - a thorough discussion of the structure of the workshops can be found in Svarre and Lunn [17]. The workshops and participant interactions were captured on video, dictation machine, and pictures to allow for analysis. After the workshops, the sound files were transcribed by an external transcriber. The transcripts were then subjected to meaning condensation and coding [18] with the purpose of identifying likely challenges, potential, differences of opinion, and requirements for the future application. The analysis led to the delineation of the requirements listed in Section 4.

Subsequently, we started developing design proposals for the mobile application. Throughout the development process, we worked closely with an IT company that was in charge of programming the application. The process was iterative, as it involved continuous alternations between programming and idea generation from the project group.

\section{Application requirements}

The two workshops served the purpose of identifying the challenges and strengths of the paper version of the tool along with general design ideas. The requirements emphasized by the workshop participants, which are presented in Table 1, ranged from generic observations to highly specific issues, problems, and ideas.

The workshops also highlighted problems concerning the general understanding and use of the tool, the correct use of the relevance criteria as an interviewer, and the amount of the time required for the tool's use. These issues were related to the generic form of the tool and would not be affected by digitization. Other issues, such as the possibility of combining the tool with other tools, establishing a hierarchy of everyday technology items, and introducing supporting questions were related to development focused on usage rather than development of the application itself. Issues that were beyond the scope of the application's development do not appear in the table. 
Table 1. Summary of characteristics, user suggestions, and design solutions

\begin{tabular}{|c|c|c|}
\hline $\begin{array}{c}\text { Issues/strengths/weaknesses/ } \\
\text { characteristics/design ideas (in relation } \\
\text { to original tool) }\end{array}$ & User suggestion & Design solution \\
\hline Structured to guide a personal conversation & $\begin{array}{l}\text { Focus on the dialogue and } \\
\text { make room for the client }\end{array}$ & $\begin{array}{l}\text { Navigation structure should } \\
\text { be simple and flexible }\end{array}$ \\
\hline Omit irrelevant items & $\begin{array}{l}\text { Only score items relevant to } \\
\text { the client }\end{array}$ & \multirow[t]{2}{*}{$\begin{array}{l}\text { No requirement to complete } \\
\text { all items and easy scoring }\end{array}$} \\
\hline Time consuming & $\begin{array}{l}\text { Rating all items requires a } \\
\text { significant amount of time }\end{array}$ & \\
\hline Many items to keep track of & $\begin{array}{l}\text { Remind of unintentionally } \\
\text { omitted items }\end{array}$ & $\begin{array}{l}\text { Visual reminders of empty } \\
\text { items during data collection } \\
\text { and in the report window }\end{array}$ \\
\hline No summary of findings & Sum up the results in a report & Visual presentation of results \\
\hline Esoteric results & $\begin{array}{l}\text { Ease dissemination to clients } \\
\text { and colleagues }\end{array}$ & \multirow{2}{*}{$\begin{array}{l}\text { Enable export of client report } \\
\text { in digital format }\end{array}$} \\
\hline Manual coding errors & $\begin{array}{l}\text { Risk of coding errors when } \\
\text { data are transferred from paper } \\
\text { to database }\end{array}$ & \\
\hline Easy to lose track of the work flow & $\begin{array}{l}\text { Need to move between issues } \\
\text { as the interview progresses }\end{array}$ & $\begin{array}{l}\text { Ease navigation and ability to } \\
\text { change ratings }\end{array}$ \\
\hline $\begin{array}{l}\text { Data and results can be compared for the } \\
\text { same client }\end{array}$ & $\begin{array}{l}\text { Digital comparison of differ- } \\
\text { ent reports for the same client }\end{array}$ & $\begin{array}{l}\text { After the client is registered, } \\
\text { several reports can be gener- } \\
\text { ated and compared }\end{array}$ \\
\hline Available in different languages & $\begin{array}{l}\text { Easy switching among lan- } \\
\text { guages }\end{array}$ & $\begin{array}{l}\text { Integrate Swedish, English, } \\
\text { and Danish language options }\end{array}$ \\
\hline
\end{tabular}

\section{$5 \quad$ Application design}

The application, which was developed for Android tablets, is structured as shown in Error! Reference source not found.. At first glance, the model appears linear, but the application's interface enables users to complete the various elements as they work their way through the interview.

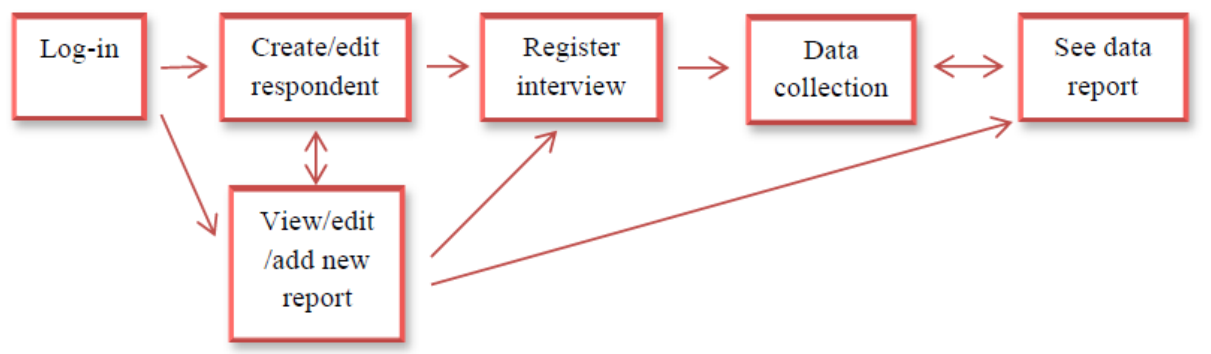

Fig. 1. Content elements of the application

For data-safety reasons, users must $\log$ in before they can use the application. Thereafter, they can create a new respondent or retrieve existing respondents. The 
data registered in this interface reflect the data specified in the original tool (e.g., gender, age, occupation). In addition, each interview session is registered to allow users to distinguish among numerous interviews when needed. Subsequently, data are collected on the respondents' difficulties with using technologies in their daily lives. For data collection, the items are grouped into seven topics to provide an overview of the items and an indication of how far the user has advanced in the interview process. On the left-hand side of the interface, a checkmark indicates when a topic has been completed (see illustration in Error! Reference source not found.), while fractions indicate how many items are completed within each topic.

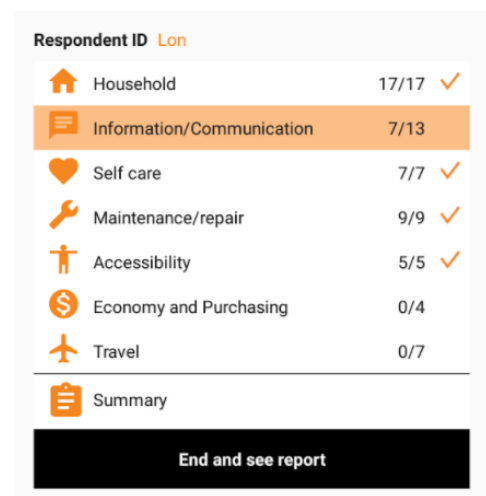

Fig. 2. The application's data-collection interface

The right-hand side of the data-collection interface shown in Error! Reference source not found. lists the items contained within a given topic. To address the workshop participants' requirement that the tool be simplified, an item only unfolds and asks for additional specifications of a technology's use if the user has indicated that the technology in question is being used.

In the report interface, the distribution of items and their degrees of difficulty, relevance, and use are illustrated (see Error! Reference source not found.). The report design is inspired by the workshops, where it became evident that clarity was important. In response to user requirements, the distribution can be viewed for a single topic or across all topics.

The flexibility requested in the workshops is incorporated in the application in different ways. For example, as illustrated in Error! Reference source not found. and 3 , the user can move among various windows while filling out items during an interview. When needed, the user can complete one or more items, go to the report window for a preliminary view of item distribution, and return to the data-collection window to complete more items. In addition, existing reports are available to the user, who can add a new report to an existing respondent or edit an existing report when needed. 


Respondent ID Lon
20. feb. $2017 \mathrm{kl} .15: 22$
A Full report
Topic areas:
A Household
Information/Communication
† Accessibility
\$ Economy and Purchasing
4 Travel

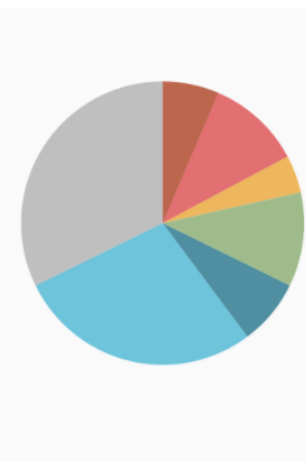

\section{Edit ETUQ report}

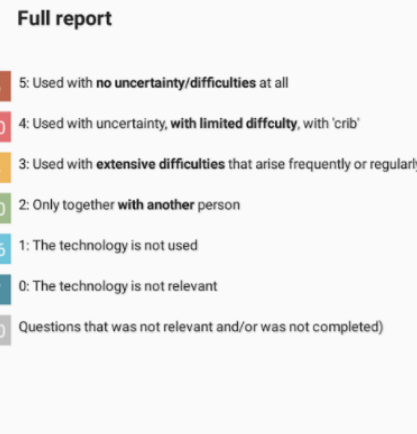

Export ETUQ to Excel Delete ETUQ report

Fig. 3. The application's report interface

\section{Discussion and future work}

The design presented above reflects the tension between designing from a known tool, as is the case here, and designing from scratch. The digitization of a tool that is already in use may limit the users, as they are restricted by the limits and format of the existing tool. However, as users have experience with the tool, they may be able to avoid the tool's known inconveniences and, thereby, end up with a stronger solution.

The work presented here reflects the initial design of a mobile application for researchers and occupational therapists in their everyday work with clients. The application was designed on the basis of information gathered during two design workshops involving current users of the paper-based version of the tool. The application is currently in testing in clinical practice with the aim of extending our knowledge of its possibilities, limitations, and applicability in interactions among therapists, clients, and mobile units. Follow-up studies should be carried out to broaden our understanding in this regard. These studies can, for example, focus on the report, which is a new feature. Moreover, attention should be paid to the data-security element and to ways in which the data can be integrated with existing systems used for research and municipal administration.

\section{Acknowledgements}

The authors wish to express their gratitude to the Department of Occupational Therapy and the University College of Northern Denmark for funding this project. 


\section{References}

[1] U. Varshney, Pervasive Healthcare Computing: EMR/EHR, Wireless and Health Monitoring. New York, 2009. https://doi.org/10.1007/978-1-4419-0215-3

[2] B. M. C. Silva, J. J. P. C. Rodrigues, I. de la Torre Díez, M. López-Coronado, and K. Saleem, "Mobile-health: A review of current state in 2015," J. Biomed. Inform., vol. 56, pp. 265-272, Aug. 2015. https://doi.org/10.1016/j.jbi.2015.06.003

[3] C. L. Ventola, "Mobile Devices and Apps for Health Care Professionals: Uses and Benefits," Pharm. Ther., vol. 39, no. 5, pp. 356-364, 2014.

[4] A. Abugabah and O. Alfarraj, "Issues to Consider in Designing Health Care Information Systems: A User-centred Design Approach,” Electron. J. Health Inform., vol. 9, no. 1, p. e8, 2015.

[5] R. Agarwal, Guodong Gao, C. DesRoches, and A. K. Jha, "The Digital Transformation of Healthcare: Current Status and the Road Ahead," Inf. Syst. Res., vol. 21, no. 4, pp. 796809, 2010. https://doi.org/10.1287/isre.1100.0327

[6] M. Chiasson, M. Reddy, B. Kaplan, and E. Davidson, "Expanding multi-disciplinary approaches to healthcare information technologies: What does information systems offer medical informatics?," Int. J. Med. Inf., vol. 76, Supplement 1, pp. S89-S97, Jun. 2007. https://doi.org/10.1016/j.ijmedinf.2006.05.010

[7] B.-T. Karsh, M. B. Weinger, P. A. Abbott, and R. L. Wears, "Health information technology: fallacies and sober realities," J. Am. Med. Inform. Assoc., vol. 17, no. 6, pp. 617-623, 2010. https://doi.org/10.1136/jamia.2010.005637

[8] U. Varshney, "Mobile health: Four emerging themes of research," Decis. Support Syst., vol. 66, pp. 20-35, Oct. 2014. https://doi.org/10.1016/j.dss.2014.06.001

[9] L. Rosenberg, L. Nygård, and A. Kottorp, "Everyday Technology Use Questionnaire: Psychometric Evaluation of a New Assessment of Competence in Technology Use," OTJR Occup. Particip. Health, vol. 29, no. 2, pp. 52-62, 2009. https://doi.org/10.3928/15394 492-20090301-05

[10] L. Nygård, L. Rosenberg, and A. Kottorp, "Everyday Technology Use Questionnaire: ETUQ,” Karolinska Institutet, Stockholm, Manual, 2015.

[11] R. S. de Almeida et al., "Development of a Hybrid Application for Psychotic Disorders Self-Management," in SpringerLink, 2017, pp. 229-237.

[12] T. Svarre, T. B. K. Lunn, and T. Helle, "Transforming paper-based assessment forms to a digital format: Exemplified by the Housing Enabler prototype app," Scand. J. Occup. Ther., vol. 24, no. 6, pp. 438-447, 2017. https://doi.org/10.1080/11038128.2016.1255774

[13] B. M. C. Silva, J. J. P. C. Rodrigues, I. de la Torre Díez, M. López-Coronado, and K. Saleem, "Mobile-health: A review of current state in 2015," J. Biomed. Inform., vol. 56, no. Supplement C, pp. 265-272, Aug. 2015.

[14] R. S. H. Istepanian, S. Laxminarayan, and C. S. Pattichis, Eds., M-Health. Boston, MA: Springer US, 2006. https://doi.org/10.1007/b137697

[15] R. Bashshur, G. Shannon, E. Krupinski, and J. Grigsby, "The Taxonomy of Telemedicine," Telemed. E-Health, vol. 17, no. 6, pp. 484-494, Jun. 2011.

[16] C. Brodersen, C. Dindler, and O. S. Iversen, "Staging imaginative places for participatory prototyping," Co-Des., vol. 4, no. 1, pp. 19-30, 2008. https://doi.org/10.1080/15710880 $\underline{701875043}$

[17] T. Svarre and T. B. K. Lunn, "Fictional Narratives for Clinical App Development," in Scandinavian Conference on Health Informatics: proceedings, Kristiansand, 2017.

[18] S. Brinkmann and S. Kvale, InterViews. SAGE Publications, 2014. https://doi.org/10.1007/978-1-4614-5583-7 161 


\section{Authors}

Tanja Svarre is an Associate Professor at Aalborg University, Department of Communication and Psychology, and a member of the research group eLearning Lab, a center for user-driven innovation, learning, and design.

Tine Bieber Kirkegaard-Lunn is a Senior Lecturer at University College of Northern Denmark, the Department of Occupational Therapy.

Article submitted 14 January 2018. Resubmitted 09 April 2018. Final acceptance 08 May 2018. Final version published as submitted by the authors. 